\title{
Kajian Ruang Budaya Nyadran Sebagai Entitas Budaya Nelayan Kupang di Desa Balongdowo - Sidoarjo
}

\author{
Faizal Ardiansyah Sangadji ${ }^{1}$, Jenny Ernawati ${ }^{2}$ dan Agung Murti Nugroho ${ }^{3}$ \\ ${ }^{1}$ Jurusan Arsitektur Lingkungan Binaan, Fakultas Teknik, Universitas Brawijaya \\ ${ }^{2}$ Jurusan Arsitektur, Fakultas Teknik, Universitas Brawijaya \\ 3 Jurusan Arsitektur, Fakultas Teknik, Universitas Brawijaya \\ burdhie@yahoo.com
}

\begin{abstract}
ABSTRAK
Desa Balongdowo Kecamatan Candi merupakan lokasi sentra permukiman nelayan kerang kupang yang terdapat di Kabupaten Sidoarjo. Setiap tahun menjelang bulan puasa masyarakat nelayan kupang melaksanakan tradisi budaya Nyadran yang menjadi ruang budaya mereka. Kajian ruang budaya dilakukan dengan menggunakan metode kualitatif dan didukung dengan observasi perilaku-lingkungan dan teori pembentukan ruang budaya. Hasil ruang-ruang budaya yang terbentuk dipengaruhi oleh tradisi budaya Nyadran mulai dari tahapan persiapan, pemberangkatan, pembuangan seekor ayam, larung sesaji, ziarah ke makam Dewi Sekardadu, peragaan pencarian kupang, dan penutup.
\end{abstract}

Kata kunci: ruang budaya, Nyadran, nelayan kupang, Balongdowo

\begin{abstract}
Balongdowo village Candi region is the location of the center of mussel shells fishing settlement located in Sidoarjo. Every year before the fasting month mussel fishing communities implement Nyadran cultural traditions that became their cultural space. Study of cultural space is done by using qualitative methods and supported by observation of behavior environment and theory formation of cultural space. Results spaces formed culture is influenced by cultural traditions Nyadran ranging from the preparation stage, the departure, the disposal of a chicken, float an offering, a pilgrimage to the tomb of the Goddess Sekardadu, search demonstration mussel, and cover .
\end{abstract}

Keywords : cultural space, Nyadran, mussel fishermen, Balongdowo

\section{Pendahuluan}

Manusia dan lingkungan mempunyai keterikatan satu sama lain. Karena itu, setiap manusia dan lingkungannya juga saling mempengaruhi. Karena lingkungan bukan hanya sebagai wadah manusia beraktifitas, melainkan juga menjadi bagian integral dari pola perilaku manusia (Lauren, 2004: 45).

Kehadiran manusia telah menciptakan ruang hidup pada lingkungan tempat tinggalnya dan alam sekitarnya (Amri,2013). Asriany (2012) berpendapat bahwa dalam hal psikologis, arsitektur memahami ruang sebagai locus terjadinya percampuran, pertemuan, atau bahkan pertempuran beragam kepentingan (needs) dan keinginan (wants) manusia.

Sekelompok manusia atau masyarakat yang bermukim di daerah pesisir umumnya bermata pencaharian sebagai nelayan karena selain lingkungan dapat mempengaruhi 
perilaku masyarakatnya dan juga karena umumnya manusia menempatkan lingkungan tempat tinggalnya berdekatan dengan tempat penghidupan mereka sehingga dapat mendukung peri kehidupan mereka.

Permukiman di Desa Balongdowo Kecamatan Candi merupakan salah satu diantara permukiman wilayah pesisir di Kabupaten Sidoarjo dan merupakan wilayah sentra permukiman nelayan tradisional dengan komoditasnya adalah kerang kupang.

Setiap tahun sebelum bulan puasa atau bulan ruwah (kalender Jawa), masyarakat nelayan kupang di Desa Balongdowo melaksanakan tradisi budaya yang biasa disebut Nyadran sebagai ungkapan syukur masyarakat nelayan atas hasil yang telah mereka peroleh.

Tradisi budaya Nyadran merupakan agenda rutin masyarakat nelayan kupang di Desa Balongdowo setiap menjelang bulan puasa dan menjadi agenda resmi Pemerintah Kabupaten Sidoarjo yang dalam pelaksanaannya banyak menggunakan ruang terbuka sehingga penggunaan fasilitas umum menjadi bagian dari tempat pelaksanaan acara tersebut.

Rencana Tata Ruang Wilayah Pemerintah Daerah Kabupaten Sidoarjo periode tahun 2009 - 2029 terdapat kebijakan untuk mengembangkan ekonomi pesisir, mengembangkan ilmu pengetahuan dan teknologi dan juga mempertahankan fungsi kawasan. Dalam sistem dan fungsi perwilayahan di Kabupaten Sidoarjo, Kecamatan Candi menjadi pusat pertumbuhan dan mempunyai fungsi utama adalah kawasan budidaya perikanan dan pariwisata yang rencananya akan dikembangkan fasilitas transportasi air, fasilitas pariwisata, terminal, balai penelitian untuk skala lokal dan regional.

Mengacu pada latar belakang tersebut, maka kajian ini bertujuan mendeskripsikan dan menggambarkan ruang budaya yang terbentuk pada saat pelaksanaan tradisi budaya Nyadran.

Bagi masyarakat Desa Balongdowo dan Pemerintah Daerah Kabupaten Sidoarjo melalui kajian ini diharapkan dapat melihat potensi yang dimiliki Desa Balongdowo sehingga dapat membangun dan mengembangkan wilayah menjadi permukiman yang berkelanjutan. Selain itu kajian ini juga diharapkan dapat menjadi dasar penelitian selanjutnya, terutama pada Desa Balongdowo Kecamatan Candi Kabupaten Sidoarjo.

\section{Metode}

Metode dalam kajian ini adalah metode kualitatif sehingga dapat menyajikan gambaran yang lengkap mengenai obyek kajian dengan mendeskripsikan aktifitas yang dilakukan dan menggambarkan setting lokasi pelaksanaan tradisi budaya Nyadran. Sebagai pendukung kajian digunakan metode observasi perilaku-lingkungan sebagai metode pengumpulan data dan teori pembentuk ruang kebudayaan sebagai metode analisis data.

\section{Hasil dan Pembahasan}

Berdasarkan pada Instrumen Pendataan Profil Desa yang diterbitkan oleh Badan Pemberdayaan Masyarakat, Perempuan dan Keluarga Berencana Kabupaten Sidoarjo tahun 2011, didapatkan keterangan bahwa Desa Balongdowo Kecamatan Candi Kabupaten Sidoarjo memiliki luas wilayah sebesar 150,478 hektare. Jumlah penduduk tahun 2011 adalah 7.049 jiwa terdiri atas jumlah laki-laki 3.679 jiwa dan jumlah perempuan 3.370 jiwa. 
Sebagian besar warga desa Balongdowo bermatapencaharian sebagai nelayan sekitar $75 \%$ jumlah penduduk dengan komoditas utama berupa kupang yang merupakan salah satu ikon kuliner khas dari Kabupaten Sidoarjo. Sedangkan sebagian kecil lainnya berprofesi sebagai petani, pegawai negeri, guru, dan pedagang.

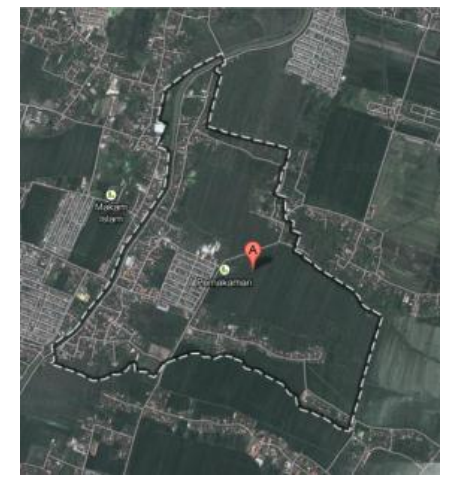

Gambar 1. Wilayah Desa Balongdowo, Kecamatan Candi Kabupaten Sidoarjo (Sumber : Citra Satelit, Data Peta @2013 Google)

Desa Balongdowo Kecamatan Candi Kabupaten Sidoarjo terdiri atas 5 dusun, antara lain yaitu: Dusun Tempel di bagian Utara, Dusun Banjarsari di bagian Utara, Dusun Meduran di bagian Selatan, Dusun Picis di bagian Tenggara, dan Dusun Balongdowo di bagian Tengah. Sedangkan batas-batas desa antara lain yaitu: sebelah utara dengan Desa Klurak Kecamatan Candi, sebelah selatan dengan Desa Putat Kecamatan Tanggulangin, sebelah timur dengan Desa Kedung Banteng Kecamatan Tanggulangin, dan sebelah barat dengan Desa Balong Gabus Kecamatan Candi.

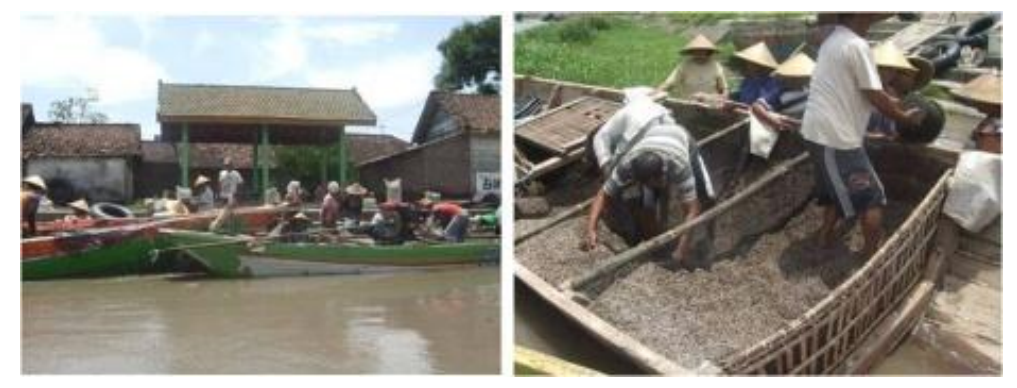

Gambar 2. Mata pencaharian mayoritas Desa Balongdowo sebagai nelayan kupang

Sejarah tradisi budaya Nyadran masyarakat nelayan kupang di Desa Balongdowo bermula dari ditemukannya jasad Putri Ayu Dewi Sekardadu (ibunda Sunan Giri) oleh nelayan Balongdowo yang digotong ramai-ramai oleh ikan keting di daerah yang akhirnya dikenal dengan Dusun Kepetingan yang terletak di Desa Sawohan Kecamatan Buduran Kabupaten Sidoarjo. Anang Ma'ruf (2010), “Nyadran sejatinya adalah upacara ritual petik laut ke makam Dewi Sekardadu yang terletak di Dusun Kepetingan Desa Sawohan Kecamatan Buduran Kabupaten Sidoarjo". 


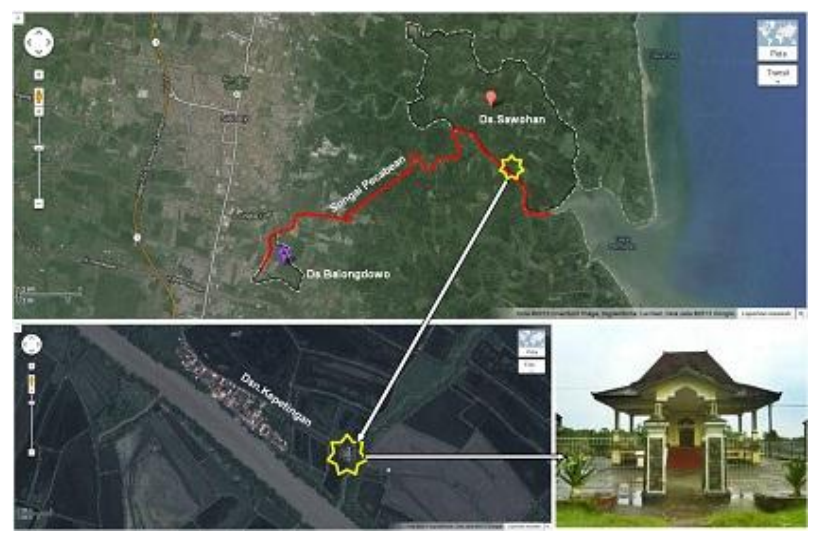

Gambar 3. Lokasi makam Dewi Sekardadu Dusun Kepetingan, Desa Sawohan, Kecamatan Buduran Kabupaten Sidoarjo

Pada tahun 2014, pelaksanaan tradisi budaya Nyadran jatuh tepatnya pada hari Minggu tanggal 8 Juni 2014. Secara umum dalam pelaksanaannya tradisi budaya Nyadran terbagi dalam 7 (tujuh) tahapan yaitu persiapan, pemberangkatan, pembuangan seekor ayam (barangan), larung sesajen, ziarah makam Dewi Sekardadu, peragaan pencarian kupang, dan pulang.

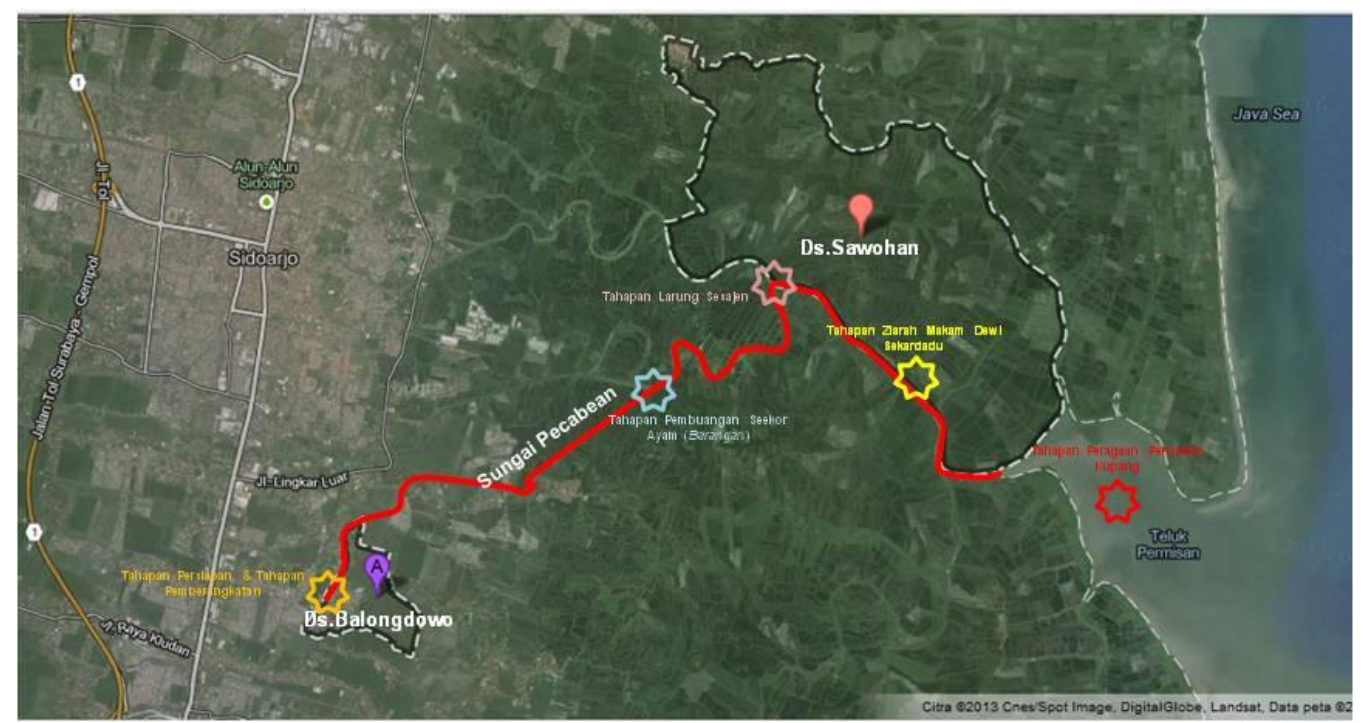

Gambar 4. Tahapan pelaksanaan pada tradisi budaya Nyadran. Tahap persiapan dan tahap pemberangkatan dilakukan dalam wilayah Desa Balongdowo, sedangkan tahapan lainnya dilakukan diluar wilayah Desa Balongdowo. Tahap pulang merupakan perjalanan pulang dari pelaksanaan tradisi budaya Nyadran

1. Tahapan persiapan merupakan aktifitas yang dilakukan setiap masyarakat nelayan kupang di Desa Balongdowo dalam rangka mempersiapkan diri untuk mengikuti acara tradisi Nyadran. Mulai dari mempersiapkan bekal makanan, sesajen, menghias perahu, hingga menyiapkan sound system termasuk dalam tahapan persiapan. 
Tabel 1. Observasi Perilaku-Lingkungan tahap persiapan

\begin{tabular}{|c|c|c|}
\hline NO & URAIAN OBSERVASI & HASIL OBSERVASI PERILAKU-LINGKUNGAN \\
\hline 1. & Who is (pelaku yang diamati). & $\begin{array}{l}\text { Masyarakat nelayan yang turut melaksanakan tradisi budaya } \\
\text { Nyadran. }\end{array}$ \\
\hline 2. & $\begin{array}{l}\text { Doing what (aktifitas yang } \\
\text { dilakukan). }\end{array}$ & $\begin{array}{l}\text { 1. Memasak bekal. } \\
\text { 2. Penataan sesaji. } \\
\text { 3. Memasak tumpeng. } \\
\text { 4. Menghias perahu. }\end{array}$ \\
\hline 3. & With whom (siapa yang terlibat). & $\begin{array}{l}\text { 1. Keluarga atau tetangga yang turut dalam satu perahu. } \\
\text { 2. Keluarga atau tetangga yang turut dalam satu perahu. } \\
\text { 3. Keluarga atau tetangga yang turut dalam satu perahu. } \\
\text { 4. Keluarga atau tetangga yang turut dalam satu perahu. }\end{array}$ \\
\hline & $\begin{array}{l}\text { In what relationship (hubungan } \\
\text { antara pelaku dengan yang terlibat). }\end{array}$ & $\begin{array}{l}\text { 1.Peserta acara Nyadran dalam satu perahu. } \\
\text { 2.Peserta acara Nyadran dalam satu perahu. } \\
\text { 3. Peserta acara Nyadran dalam satu perahu. } \\
\text { 4. Peserta acara Nyadran dalam satu perahu. }\end{array}$ \\
\hline 6. & $\begin{array}{l}\text { In } \quad \text { what } \\
\text { pengamatan) }\end{array}$ & $\begin{array}{l}\text { 1. Memasak bekal yang akan dimakan dalam perjalanan ritual } \\
\text { Nyadran. } \\
\text { 2. Menata sesaji yang akan diserahkan pada saat ziarah ke } \\
\text { makam Dewi Sekardadu. } \\
\text { 3. Memasak tumpeng yang akan menjadi simbol dimulainya } \\
\text { ritual budaya Nyadran. } \\
\text { 4. Mempersiapkan perahu yang akan digunakan dalam } \\
\text { mengikuti ritual budaya Nyadran. }\end{array}$ \\
\hline & Where (tempat pengamatan) & $\begin{array}{l}\text { 1. Ruang Mikro dan bersifat semi publik (dapur dan teras } \\
\text { rumah). } \\
\text { 2. Ruang Mikro dan bersifat semi publik (teras rumah). } \\
\text { 3. Ruang Mikro dan bersifat privat (dapur). } \\
\text { 4. Ruang Meso dan bersifat publik (bantaran sungai). }\end{array}$ \\
\hline
\end{tabular}

Mengacu pada tabel 1. maka dapat diperhatikan gambar setting-nya pada gambar 5. dan gambar 6. sebagai berikut.

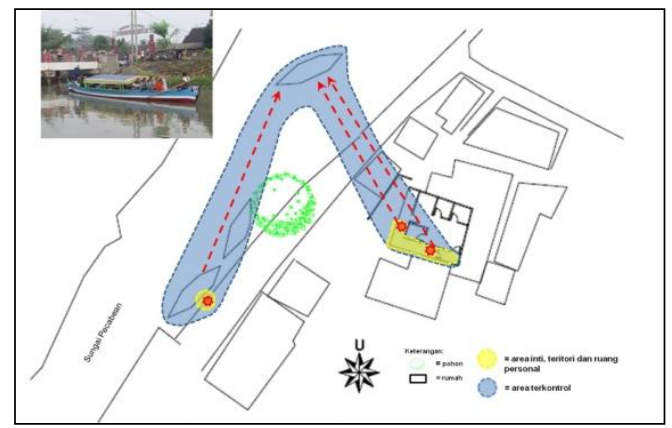

Gambar 5. Setting ruang pada tahapan persiapan (memasak bekal pada teras dan menghias perahu di bantaran sungai)

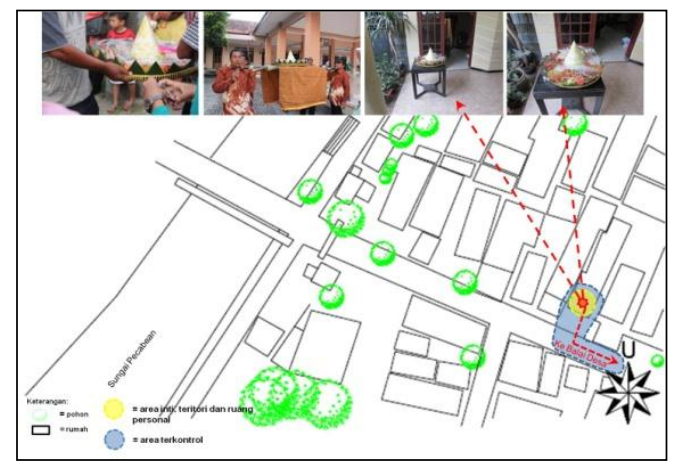


Gambar 6. Setting ruang pada tahapan persiapan (pembuatan tumpeng yang kemudian dibawa ke balai desa)

Hasil analisa pembentuk ruang kebudayaan yang terjadi pada tahap persiapan adalah Adanya masyarakat yang menarik perhatian dalam aktifitas tertentu dan mempunyai suara yang terlihat pada persiapan perahu dan pemasangan sound system pada perahu.

2. Tahapan pemberangkatan merupakan tahapan yang dilaksanakan meliputi iring-iringan tumpeng mulai dari balai desa sampai dengan dermaga tempat pemberangkatan. Setelah acara pemberangkatan dilakukan barulah para perahu peserta Nyadran memulai perjalanannya sejauh 12 kilometer menuju muara laut.

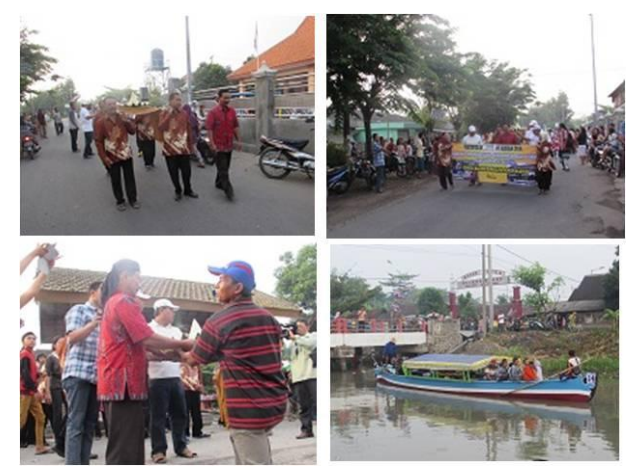

Gambar 7. Tahapan Pemberangkatan

Tabel 2. Observasi Perilaku-Lingkungan tahap pemberangkatan

\begin{tabular}{|c|c|c|}
\hline NO & URAIAN OBSERVASI & HASIL OBSERVASI PERILAKU-LINGKUNGAN \\
\hline 1. & Who is (pelaku yang diamati). & $\begin{array}{l}\text { Masyarakat nelayan yang turut melaksanakan tradisi budaya } \\
\text { Nyadran. }\end{array}$ \\
\hline 2. & $\begin{array}{l}\text { Doing what (aktifitas yang } \\
\text { dilakukan). }\end{array}$ & $\begin{array}{l}\text { 1. Iring-iringan tumpeng. } \\
\text { 2. Berdoa bersama. } \\
\text { 3. Pemotongan tumpeng. }\end{array}$ \\
\hline 4. & With whom (siapa yang terlibat). & $\begin{array}{l}\text { 1. Perangkat Desa Balongdowo, drum band TK.Dharma Wanita, } \\
\text { Kelompok Hadrah. } \\
\text { 2. Kepala Desa, Perangkat Desa, Ketua Nelayan, masyarakat } \\
\text { nelayan. } \\
\text { 3. Kepala Desa, Perangkat Desa, Ketua Nelayan. }\end{array}$ \\
\hline & $\begin{array}{l}\text { In what relationship (hubungan } \\
\text { antara pelaku dengan yang terlibat). }\end{array}$ & $\begin{array}{l}\text { 1. Warga Desa Balongdowo dalam mendukung pelaksanaan } \\
\text { ritual Nyadran. }\end{array}$ \\
\hline 5. & $\begin{array}{l}\text { In what context (situasi } \\
\text { pengamatan) }\end{array}$ & $\begin{array}{l}\text { 2. Penyelenggara dan peserta acara ritual Nyadran. } \\
\text { 3. Penyelenggara dan peserta acara ritual Nyadran. }\end{array}$ \\
\hline 6. & Where (tempat pengamatan) & $\begin{array}{l}\text { 1. Memeriahkan pelaksanaan ritual Nyadran. } \\
\text { 2. Ritual pertama dalam ritual Nyadran. } \\
\text { 3. Simbol dimulainya ritual budaya Nyadran. } \\
\text { 1. Ruang Meso dan bersifat publik (dari Balai Desa menuju } \\
\text { tempat pemberangkatan). } \\
\text { 2. Ruang Meso dan bersifat publik (dermaga tempat } \\
\text { pemberangkatan ritual Nyadran). } \\
\text { 3. Ruang Meso dan bersifat publik (dermaga tempat } \\
\text { pemberangkatan ritual Nyadran). }\end{array}$ \\
\hline
\end{tabular}

Mengacu pada tabel 2. maka dapat diperhatikan gambar setting-nya pada gambar 8 . sebagai berikut. 


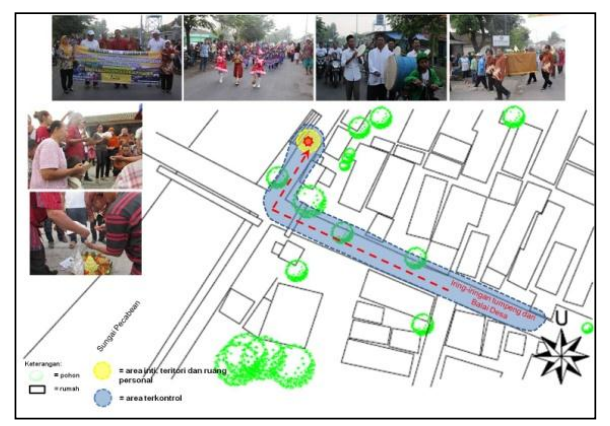

Gambar 8. Setting ruang pada tahapan pemberangkatan (iring-iringan tumpeng dari balai desa menuju dermaga pemberangkatan kemudian berdoa bersama dan pemotongan tumpeng)

Hasil analisa pembentuk ruang kebudayaan yang terjadi pada tahapan pemberangkatan adalah sebagai berikut: lokasi (dermaga); mempunyai suara (proses iring-iringan tumpeng dari balai desa dan proses berdoa bersama); Adanya masyarakat yang menarik perhatian dalam aktifitas tertentu (iring-iringan tumpeng dari balai desa, berdoa bersama, pemotongan tumpeng).

3. Tahapan pembuangan seekor ayam (barangan), merupakan salah satu tahapan ritual Nyadran yang dilakukan pada muara sungai pecabean dengan tujuan untuk menghindari malapetaka atau bencana bagi pengikut acara ritual Nyadran khususnya anak balita agar tidak kesurupan melalui pembuangan seekor ayam hidup ke sungai. Proses pembuangan ayam tersebut dikenal dengan barangan.

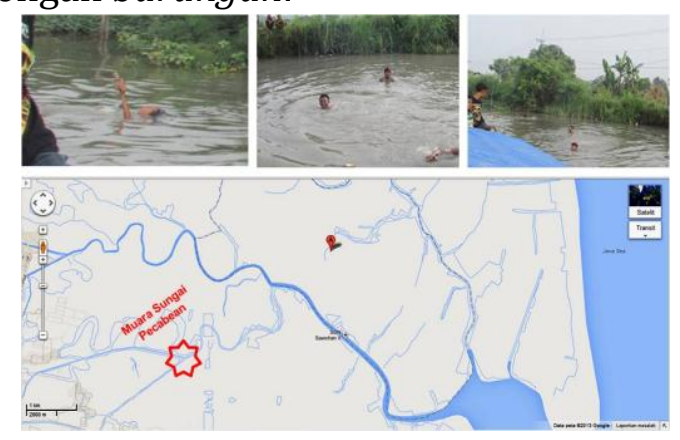

Gambar 9. Tahapan pembuangan seekor ayam (barangan).

Tabel 3. Observasi Perilaku-Lingkungan pada tahap pembuangan ayam (barangan)

\begin{tabular}{|c|c|c|}
\hline NO & URAIAN OBSERVASI & HASIL OBSERVASI PERILAKU-LINGKUNGAN \\
\hline 1. & Who is (pelaku yang diamati). & $\begin{array}{l}\text { Masyarakat nelayan yang turut melaksanakan tradisi budaya } \\
\text { Nyadran. }\end{array}$ \\
\hline 2. & $\begin{array}{l}\text { Doing what (aktifitas yang } \\
\text { dilakukan). }\end{array}$ & 1. Pembuangan seekor ayam. \\
\hline 3. & With whom (siapa yang terlibat). & $\begin{array}{l}\text { 1. Perahu peserta tradisi budaya Nyadran yang membawa } \\
\text { balita. }\end{array}$ \\
\hline 5. & $\begin{array}{l}\text { In what relationship (hubungan } \\
\text { antara pelaku dengan yang terlibat). }\end{array}$ & 1. Peserta tradisi budaya Nyadran yang membawa balita. \\
\hline 6. & $\begin{array}{l}\text { In what context (situasi } \\
\text { pengamatan) }\end{array}$ & $\begin{array}{l}\text { 1. Permohonan agar terhindar dari celaka khususnya balita agar } \\
\text { tidak kesurupan. }\end{array}$ \\
\hline & Where (tempat pengamatan) & 1. Ruang Makro dan bersifat publik (muara Sungai Pecabean). \\
\hline
\end{tabular}


Mengacu pada tabel 3. maka dapat diperhatikan gambar setting-nya pada gambar 10 . sebagai berikut.

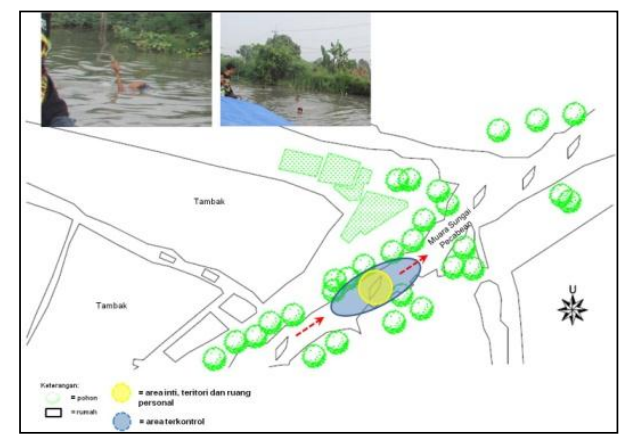

Gambar 10. Setting ruang pada tahapan pembuangan seekor ayam (muara Sungai Pecabean).

Hasil analisa pembentuk ruang kebudayaan yang terjadi pada tahapan pembuangan seekor ayam (barangan) adalah sebagai berikut: lokasi (muara Sungai Pecabean); berhubungan dengan bentang alam (Sungai Pecabean); diberi nama dengan cara yang khusus (lokasi barangan); Adanya masyarakat yang menarik perhatian dalam aktifitas tertentu (peserta tradisi budaya Nyadran yang melakukan pembuangan seekor ayam).

4. Tahapan larung sesajen merupakan tahapan yang dilakukan pada pertigaan kali anak agar peserta dapat terhindari dari pusaran air sungai karena tempat ini adalah tempat pertemuan arus air sungai sehingga rawan terjadi pusaran air. Tahapan larung sesajen dilakukan dengan melarungkan sesaji atau disebut dengan cobakal.

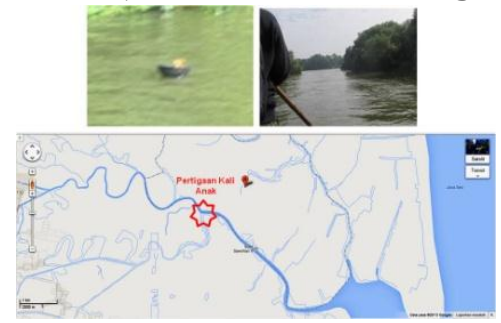

Gambar 11. Tahapan larung sesajen.

Tabel 4. Observasi Perilaku-Lingkungan pada tahap larung sesajen

\begin{tabular}{|c|c|c|}
\hline NO & URAIAN OBSERVASI & HASIL OBSERVASI PERILAKU-LINGKUNGAN \\
\hline 1. & Who is (pelaku yang diamati). & Masyarakat nelayan yang turut melaksanakan tradisi budaya \\
\hline 2. & Doing what (aktifitas yang & \\
\hline 3. & With whom (siapa yang terlibat). & 1. Perahu peserta tradisi budaya Nyadran. \\
\hline 4. & $\begin{array}{l}\text { In what relationship (hubungan } \\
\text { antara pelaku dengan yang terlibat). }\end{array}$ & 1. Peserta tradisi budaya Nyadran. \\
\hline 6. & $\begin{array}{l}\text { In what context (situasi } \\
\text { pengamatan) }\end{array}$ & 1. Permohonan agar terhindar pusaran air. \\
\hline & Where (tempat pengamatan) & 1. Ruang Makro dan bersifat publik (pertigaan Kali Anak). \\
\hline
\end{tabular}

Mengacu pada tabel 4. maka dapat diperhatikan gambar setting-nya pada gambar 12 . sebagai berikut. 


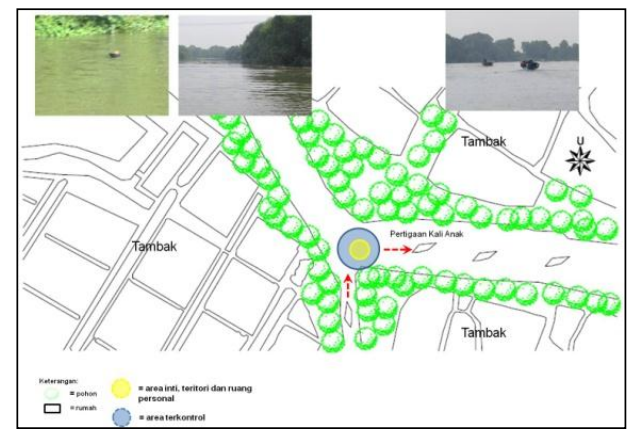

Gambar 12. Setting ruang pada tahapan larung sesajen (pertigaan Kali Anak).

Hasil analisa pembentuk ruang kebudayaan yang terjadi pada tahapan larung sesajen adalah sebagai berikut: lokasi (pertigaan Kali Anak); berhubungan dengan bentang alam (Kali Anak); diberi nama dengan cara yang khusus (lokasi larung sesajen); Adanya masyarakat yang menarik perhatian dalam aktifitas tertentu (peserta tradisi budaya Nyadran yang melakukan larung sesaji).

5. Tahapan ziarah ke makam Dewi Sekardadu merupakan acara puncak atau acara utama dalam ritual Nyadran yang dilakukan oleh nelayan kupang di Desa Balongdowo. Ketika sampai pada Desa Sawohan tepatnya Dusun Kepetingan seluruh rombongan perahu berhenti dan peserta turun untuk mengunjungi makam Dewi Sekardadu. Pada makam Dewi Sekardadu tersebut masyarakat melakukan doa bersama dan menyerahkan sajian berupa makanan dan buah.

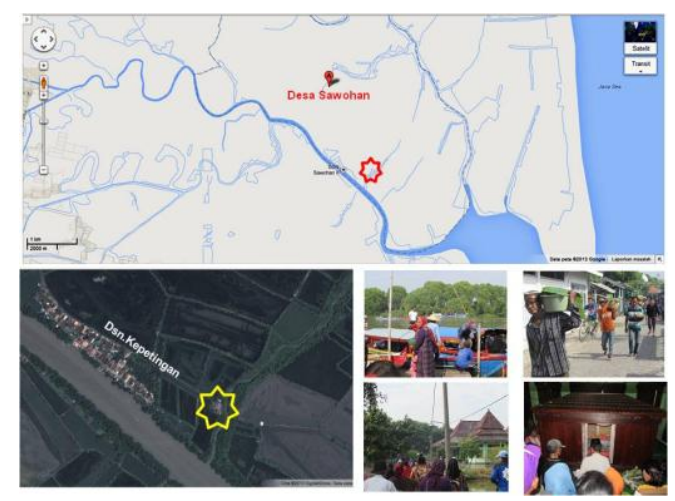

Gambar 13. Tahapan ziarah ke makam Dewi Sekardadu.

Tabel 5. Observasi Perilaku-Lingkungan tahap ziarah ke makam Dewi Sekardadu

\begin{tabular}{|c|c|c|}
\hline NO & URAIAN OBSERVASI & HASIL OBSERVASI PERILAKU-LINGKUNGAN \\
\hline 1. & Who is (pelaku yang diamati). & $\begin{array}{l}\text { Masyarakat nelayan yang turut melaksanakan tradisi budaya } \\
\text { Nyadran. }\end{array}$ \\
\hline 2. & $\begin{array}{l}\text { Doing what (aktifitas yang } \\
\text { dilakukan). }\end{array}$ & 1. Ziarah ke makam Dewi Sekardadu. \\
\hline & With whom (siapa yang terlibat). & $\begin{array}{l}\text { 1. Peserta tradisi budaya Nyadran. } \\
\text { 2. Warga Dusun Kepetingan. }\end{array}$ \\
\hline 5. & $\begin{array}{l}\text { In what relationship (hubungan } \\
\text { antara pelaku dengan yang terlibat). }\end{array}$ & $\begin{array}{l}\text { 1. Peserta tradisi budaya Nyadran. } \\
\text { 2. Tuan rumah lokasi makam Dewi Sekardadu dan Juru Kunci } \\
\text { makam. }\end{array}$ \\
\hline 6. & $\begin{array}{l}\text { In what context (situasi } \\
\text { pengamatan) }\end{array}$ & $\begin{array}{l}\text { 1. Perjalanan kaki menuju makam Dewi Sekardadu. } \\
\text { 2. Penyerahan sajian berupa makanan dan buah. } \\
\text { 3. Memanjatkan doa untuk Dewi Sekardadu. }\end{array}$ \\
\hline
\end{tabular}


Mengacu pada tabel 5. maka dapat diperhatikan gambar setting-nya pada gambar 14 . sebagai berikut.

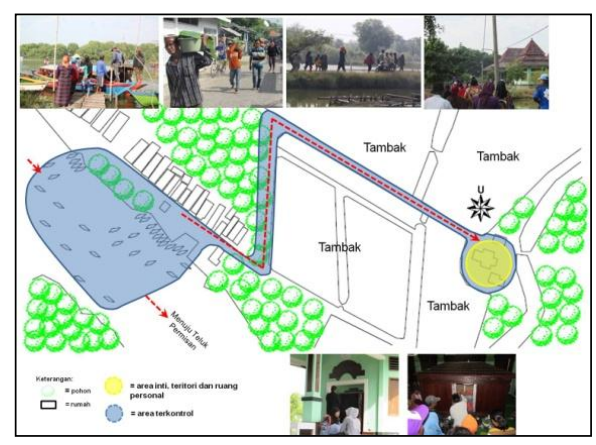

Gambar 14. Setting ruang pada tahapan ziarah ke makam Dewi Sekardadu (Dusun Kepetingan).

Hasil analisa pembentuk ruang kebudayaan yang terjadi pada tahapan ziarah ke makam Dewi Sekardadu adalah sebagai berikut: lokasi (makam Dewi Sekardadu di Dusun Kepetingan); Adanya masyarakat yang menarik perhatian dalam aktifitas tertentu (peserta tradisi budaya Nyadran yang melakukan ziarah).

6. Tahapan peragaan pencarian kupang merupakan tahapan yang dilakukan pada muara sungai di Teluk Permisan. Dalam tahapan ini peserta menceburkan diri di laut dan memperagakan cara mencari kupang.

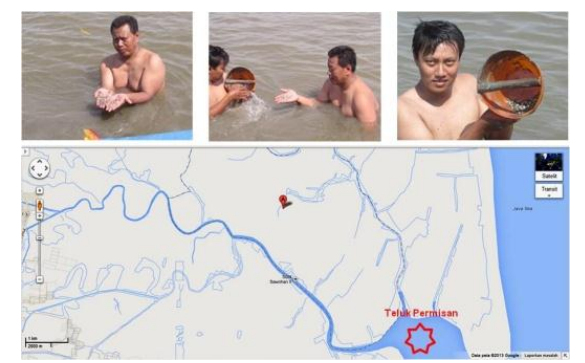

Gambar 15. Tahapan peragaan pencarian kupang

Tabel 6. Observasi Perilaku-Lingkungan pada tahap peragaan pencarian kupang

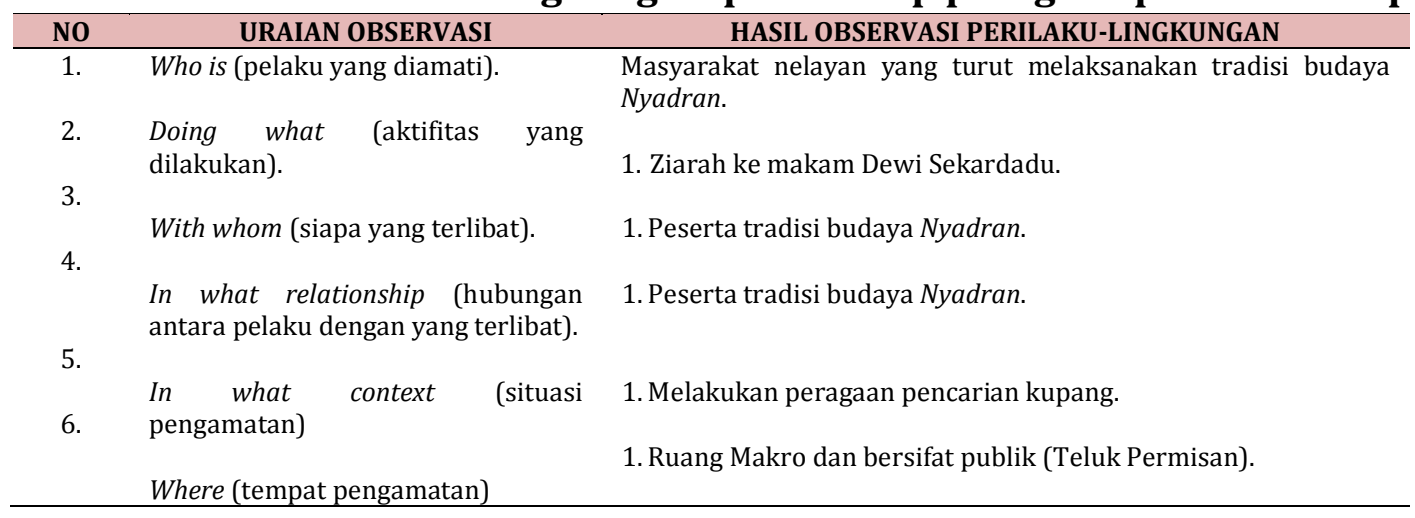


Mengacu pada tabel 6. maka dapat diperhatikan gambar setting-nya pada gambar 16. sebagai berikut.

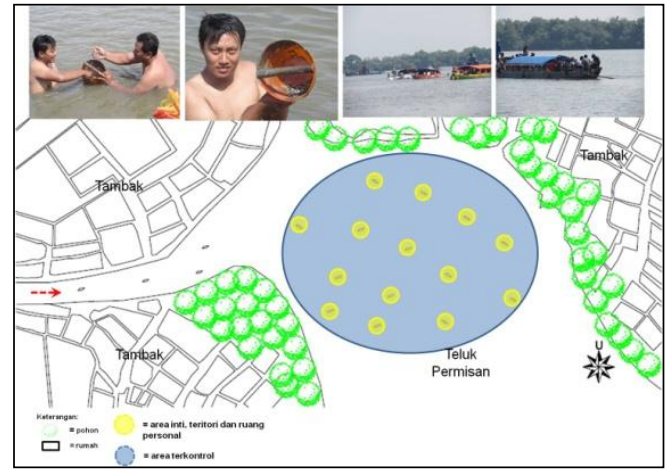

Gambar 16. Setting ruang pada tahapan peragaan pencarian kupang (Teluk Permisan).

Hasil analisa pembentuk ruang kebudayaan yang terjadi pada tahapan peragaan pencarian kupang adalah sebagai berikut: lokasi (Teluk Permisan); Adanya masyarakat yang menarik perhatian dalam aktifitas tertentu (peserta tradisi budaya Nyadran yang melakukan peragaan pencarian kupang).

7. Tahapan penutup merupakan tahapan terakhir dari rangkaian acara ritual Nyadran yaitu pulang kembali ke Desa Balongdowo.

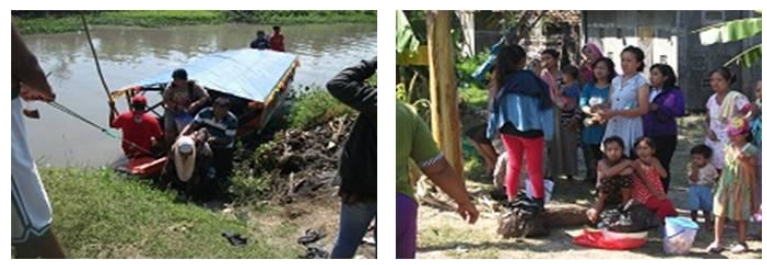

Gambar 17. Tahapan penutup.

Tabel 7. Observasi Perilaku-Lingkungan pada tahap penutup

\begin{tabular}{|c|c|c|}
\hline NO & URAIAN OBSERVASI & HASIL OBSERVASI PERILAKU-LINGKUNGAN \\
\hline 1. & Who is (pelaku yang diamati). & $\begin{array}{l}\text { Masyarakat nelayan yang turut melaksanakan tradisi budaya } \\
\text { Nyadran. }\end{array}$ \\
\hline 2. & $\begin{array}{l}\text { Doing what (aktifitas yang } \\
\text { dilakukan). }\end{array}$ & 1. Perjalanan pulang. \\
\hline & With whom (siapa yang terlibat). & 1. Keluarga atau tetangga yang turut dalam satu perahu. \\
\hline & $\begin{array}{l}\text { In what relationship (hubungan } \\
\text { antara pelaku dengan yang terlibat). }\end{array}$ & 1. Peserta tradisi budaya Nyadran yang turut dalam satu perahu. \\
\hline 6. & $\begin{array}{l}\text { In what context } \quad \text { (situasi } \\
\text { pengamatan) }\end{array}$ & 1. Kembali pulang dari perjalanan tradisi budaya Nyadran. \\
\hline & Where (tempat pengamatan) & $\begin{array}{l}\text { 1. Ruang Meso dan bersifat publik (dermaga tempat } \\
\text { pemberhentian perahu yang dekat dengan rumah pelaku). }\end{array}$ \\
\hline
\end{tabular}

Mengacu pada tabel 7. maka dapat diperhatikan gambar setting-nya pada gambar 18. sebagai berikut. 


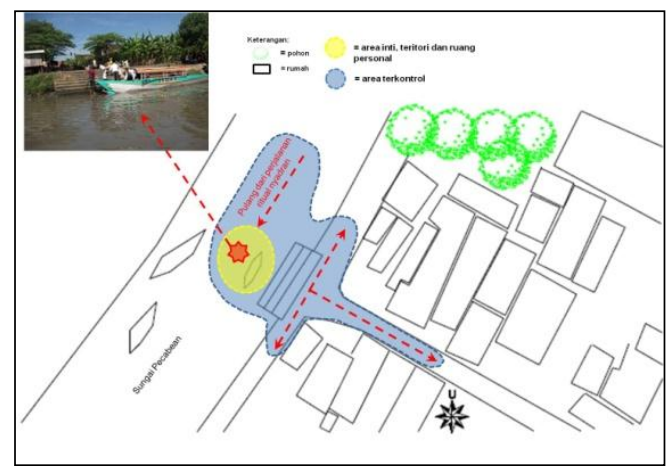

Gambar 18. Setting ruang pada tahapan penutup (perjalanan pulang sampai dengan dermaga terdekat dengan rumah dan kemudian para penumpang perahu kembali pulang ke rumah masing-masing)

Hasil analisa pembentuk ruang kebudayaan yang terjadi pada tahapan penutup adalah sebagai berikut: lokasi (dermaga); Adanya masyarakat yang menarik perhatian dalam aktifitas tertentu (peserta tradisi budaya Nyadran yang melakukan perjalanan pulang).

\section{Kesimpulan}

Tradisi budaya Nyadran merupakan tradisi budaya yang telah turun temurun dilaksanakan oleh masyarakat nelayan kupang di Desa Balongdowo dan juga merupakan entitas budaya yang dimiliki oleh masyarakat nelayan kupang di Desa Balongdowo karena mempunyai ciri khas yang terlihat pada tahapan-tahapan dalam pelaksanaannya dan tidak didapatkan pada daerah lain.

Setiap tahapan yang dilakukan dalam pelaksanaan tradisi budaya Nyadran mulai dari tahapan persiapan, tahapan pemberangkatan, tahapan pembuangan seekor ayam, tahapan larung sesaji, tahapan ziarah ke makam Dewi Sekardadu, tahapan peragaan pencarian kupang dan terakhir tahapan penutup, menggunakan ruang-ruang dan termasuk dalam kriteria terbentuknya ruang kebudayaan. Sehingga ruang-ruang yang digunakan untuk melakukan setiap tahapan pelaksanaan tradisi budaya Nyadran dapat disebut sebagai Ruang Budaya Nyadran yang menjadi entitas budaya bagi masyarakat nelayan kupang di Desa Balongdowo.

Hasil kajian ini menunjukkan secara jelas potensi ruang budaya di Desa Balongdowo melalui entitas budayanya yaitu tradisi budaya Nyadran sehingga dapat menjadi dasar untuk mendorong Pemerintah Daerah Kabupaten Sidoarjo untuk segera melaksanakan programnya sesuai Rencana Tata Ruang Wilayah Daerah Kabupaten Sidoarjo periode tahun $2009-2029$.

\section{Daftar Pustaka}

Amri, N. (2013). Karakteristik Lingkungan Permukiman Kumuh Tepian Sungai Kecamatan Kolaka, Sulawesi Tenggara. JUPITER vol.XII no.1.

Asriany, S. (2012). Dinamika Ruang Publik Eksklusif dan Inklusif Pada Permukiman Masyarakat Menengah Kebawah, Studi Kasus Permukiman Panakkukang - Makassar. Dalam J. Silas, Format-Format Perubahan Ruang (hal. 325-424). Tunggal Sakti. 
Badan Pemberdayaan Masyarakat, P. d. (2011). Instrumen Pendataan Profil Desa. Sidoarjo. Citra Satelit, Data Peta. (2013). Dipetik July 23, 2013, dari www.googlemap.com

Laurens, J. M. (2004). Arsitektur dan Perilaku Manusia. Grasindo.

Nyadran Bersama Masyarakat Balongdowo Candi. (2013, June 23). Dipetik July 18, 2013, dari kabar sidoarjo: www.kabarsidoarjo.com

Rapoport, A. (1983). Environmental Quality, Metropolitan Areas and Traditional Settlement. Pergamon Press Ltd.

Sidoarjo, P. K. (2009). Peraturan Daerah Kabupaten Sidoarjo Tentang Rencana Tata Ruang Wilayah Kabupaten Sidoarjo 2009-2029. Sidoarjo.

Zeisel, J. (2006). Inquiry by Design. W. W. Norton \& Company. 